\title{
Adubação nitrogenada orgânica influencia na classificação comercial de batatas cv.
}

\section{Asterix}

Organic nitrogen fertilization affecting commercial classification of potatoes cv. Asterix

Fertilización orgánica con nitrógeno influencia en la clasificación comercial de patatas cv. Asterix

Recebido: 02/04/2021 | Revisado: 11/04/2021 | Aceito: 19/04/2021 | Publicado: 04/05/2021

Pedro Henrique Girotto

ORCID: https://orcid.org/0000-0001-9793-4114

Universidade Federal da Fronteira Sul, Brasil

E-mail: girotto953@gmail.com

Gabriela Gerhardt da Rosa

ORCID: https://orcid.org/0000-0002-5023-3414 CEDUP - Professor Jaldyr Bhering Faustino da Silva, Brasil

E-mail: birela89@gmail.com

Edemar Jose Baranek

ORCID: https://orcid.org/0000-0002-6412-8439 Universidade Federal da Fronteira Sul, Brasil E-mail: edemar.baranek@uffs.edu.br

Jackson Kawakami

ORCID: https://orcid.org/0000-0003-2422-1564 Universidades Estaduais do Centro-Oeste, Brasil

E-mail: jkawakami@unicentro.br

Cláudia Simone Madruga Lima

ORCID: https://orcid.org/0000-0002-1953-1552

Universidade Federal da Fronteira Sul, Brasil

E-mail: claudia.lima@uffs.edu.br

\begin{abstract}
Resumo
Objetivou-se verificar a influência de diferentes adubos orgânicos e doses de nitrogênio na classificação comercial de batata cultivar Asterix. O experimento foi realizado na Universidade Federal da Fronteira Sul, setor de Horticultura. O delineamento experimental foi em blocos ao acaso, com 16 tratamentos ( 3 fontes de nitrogênio x 5 doses e 1 testemunha) e 4 repetições, totalizando 64 parcelas. As variáveis avaliadas foram comprimento/diâmetro transversal calibre $(\mathrm{mm})$, diâmetro $(\mathrm{mm})$, massa fresca $(\mathrm{g})$, defeitos graves (podridão, coração negro e coração oco), defeitos leves (embonecado, queimado, rizoctonioze e vitrificação) e defeitos variáveis (esverdeamento, dano superficial e perfurações por larva alfinete). Em todos os tubérculos colhidos não foi observado esverdeamento, queima, podridão, rizocotonioze, coração negro e vitrificação. Houve incremento do comprimento, diâmetro e massa fresca de tubérculos de batata da cultivar Asterix, conforme o aumento da dose de cama curtida utilizada. Quando as fontes de adubo são comparadas com a testemunha (adubação NPK), para essas variáveis, os valores são superiores somente para dose de $200 \mathrm{kgN} \cdot \mathrm{ha}^{-1}$ utilizando a fonte cama curtida. A fonte de adubo orgânico cama curtida na dose 200 $\mathrm{kgN} \cdot \mathrm{ha}^{-1}$ favoreceu a produção de tubérculos de batata cv. Asterix com características aptas para classificação comercial, nas condições impostas pelo experimento.
\end{abstract}

Palavras-chave: Solanum tuberosum L.; Cama de aviário curtida; Cama de aviário extrusada; Húmus.

\begin{abstract}
The objective was to verify the influence of different organic fertilizers and nitrogen doses in the commercial classification of potato cultivar Asterix. The experiment was carried out at the Federal University of Fronteira Sul, Horticulture sector. The experimental design was in randomized blocks, with 16 treatments ( 3 nitrogen sources x 5 doses and 1 control) and 4 repetitions, totaling 64 plots. The variables evaluated were length / transverse diameter caliber $(\mathrm{mm})$, diameter $(\mathrm{mm})$, fresh weight $(\mathrm{g})$, serious defects (rot, black heart and hollow heart), slight defects (embonized, burnt, rhizoctonioze and vitrification) and defects variables (greening, superficial damage and pinworm perforations). In all the harvested tubers, no greening, burning, rot, rhizochotonioze, black heart and vitrification were observed. There was an increase in the length, diameter and fresh weight of potato tubers of the Asterix cultivar, as the dose of tanned bed used increased. When the fertilizer sources are compared with the control (NPK fertilization), for these variables, the values are higher only for $200 \mathrm{kgN}$.ha-1 using the tanned bed source. The source of organic fertilizer bed tanned in the dose $200 \mathrm{kgN}$.ha -1 favored the production of potato tubers cv. Asterix with characteristics suitable for commercial classification, under the conditions imposed by the experiment.
\end{abstract} Keywords: Solanum tuberosum L.; Tanned aviary bed; Extruded poultry litter; Humus. 


\begin{abstract}
Resumen
El objetivo fue verificar la influencia de diferentes fertilizantes orgánicos y dosis de nitrógeno en la clasificación comercial del cultivar de papa Asterix. El experimento se llevó a cabo en la Universidad Federal de Fronteira Sul, sector Horticultura. El diseño experimental fue en bloques al azar, con 16 tratamientos ( 3 fuentes de nitrógeno x 5 dosis y 1 control) y 4 repeticiones, totalizando 64 parcelas. Las variables evaluadas fueron longitud / diámetro transversal - calibre $(\mathrm{mm})$, diámetro $(\mathrm{mm})$, peso fresco $(\mathrm{g})$, defectos graves (podredumbre, corazón negro y corazón hueco), defectos leves (embonizado, quemado, rizoctonioze y vitrificación) y defectos. variables (enverdecimiento, daño superficial y perforaciones por oxiuros). En todos los tubérculos recolectados, no se observaron enverdecimiento, quemaduras, pudrición, rizocotonioze, corazón negro y vitrificación. Hubo un aumento en la longitud, diámetro y peso fresco de los tubérculos de papa del cultivar Asterix, de acuerdo con el aumento en la dosis de lecho curtido utilizado. Cuando se comparan las fuentes de fertilizante con el control (fertilización NPK), para estas variables, los valores son mayores solo para una dosis de $200 \mathrm{kgN}$.ha-1 utilizando la fuente de lecho curtido. La fuente de fertilizante orgánico de lecho curtido a una dosis de $200 \mathrm{kgN}$.ha -1 favoreció la producción de tubérculos de papa cv. Asterix con características aptas para clasificación comercial, en las condiciones impuestas por el experimento.
\end{abstract}

Palabras clave: Solanum tuberosum L.; Cama de pajarera bronceada; Arena para aves de corral extruida; Humus.

\title{
1. Introdução
}

A batata (Solanum tuberosum L.) é o quarto alimento mais consumido no mundo, sendo a área cultivada de aproximadamente 19,5 milhões de hectares, distribuída por mais de 150 países (FAO, 2020). No Brasil, destaca-se por sua importância socioeconômica, sendo uma atividade praticada por um expressivo contingente de pequenos produtores (FAO, 2020). A área cultivada com batata é cerca de 134 mil hectares, e a produção nacional foi de mais de 3,9 milhões de toneladas, com destaque para os estados de Minas Gerais, Paraná e São Paulo, que são responsáveis pela maior porcentagem de toda a batata produzida no país (IBGE, 2020).

Entre as cultivares mais utilizadas no país está a Asterix (Silva et al., 2017, p.493). Originária da Holanda apresenta alto vigor e potencial produtivo, teor de massa seca de médio a alto (22,9\%), tubérculos médios a grandes (entre $45 \mathrm{~mm}$ e 85 mm de diâmetro), forma oval-alongada, uniforme, casca de cor vermelha, resistente a danos mecânicos. Apresenta características tanto para o cozimento quanto para fritura, sendo empregada industrialmente na fabricação de pré-fritas congeladas em função do seu formato oval-alongado que propicia um ótimo aproveitamento no corte em palitos (Silva et al., 2017, p.494).

A cultura da batata apresenta ciclo relativamente curto, três a quatro meses, com alta produção por área, sendo deste modo, exigente quanto ao fornecimento de nutrientes (Soratto et al., 2016, p.420). Assim, no cultivo da batata em sistemas intensivos/ convencionais, normalmente são utilizadas altas doses de fertilizantes químicos sintéticos, sendo esta uma das culturas com maior demanda de nutrientes (Queiroz et al., 2013, p.121). Entretanto, vários destes nutrientes podem não ser absorvidos completamente pelas plantas e representarem risco de poluição ambiental, fator que pode ser agravado pela alta demanda da utilização de agrotóxicos, tendo em vista que a cultura é suscetível ao ataque de doenças e pragas que acabam deteriorando o tubérculo que perde espaço no mercado (Fernandes et al., 2011, p.2041).

Em contrapartida, a crescente preocupação com a saúde do ambiente de cultivo, principalmente com o solo, e com as pessoas envolvidas no setor, desde os produtores rurais até o consumidor, tem surgido alternativas ao cultivo convencional, o cultivo orgânico, que visa práticas agronômicas sustentáveis e melhoria das condições ambientais (Reichert et al., 2013, p.222). Entretanto, o cultivo orgânico de batatas é um desafio, iniciando pela escolha de cultivares adaptadas (Silva et al., 2012, p.494), pela suscetibilidade da planta a doenças e pragas (Maraus et al., 2011, p.475), bem como o adequado momento para o fornecimento e aporte de nutrientes para o pleno desenvolvimento da cultura (Palmer et al., 2013, p.85; Musyoka et al., 2017, p.26).

A adubação é um dos principais fatores de interferência na produtividade, qualidade e nas características pós-colheita da batata (Soratto et al., 2016, p.420). Entre os adubos que podem ser utilizados em cultivo orgânico citam-se estercos bovinos, 
cama de aviário e o húmus que são de fácil aquisição e valor acessível aos produtores rurais (Richter \& Randomski, 2009, p.29; Musyoka et al., 2017, p.26). A adubação orgânica proporciona a longo prazo, benefícios na parte química, física e biológica do solo, devido ao acúmulo de matéria orgânica no solo (Malavolta, 2006).

A adubação orgânica, ao longo dos anos, promove incremento do carbono orgânico total, da estabilidade dos agregados em água, dos teores de $\mathrm{P}$ e de $\mathrm{N}$ nas diferentes classes de agregados do solo e diminui a relação $\mathrm{C} / \mathrm{N}$ (Matos et al., 2008, p.1223). Sendo este também um fator benéfico, pois o nitrogênio é um nutriente determinante na produtividade da batateira, por ser um elemento limitante, poderá afetar diretamente a produção (Fernandes et al., 2011, p.2041). Se aplicado em excesso, prolongará o período vegetativo, acarretando atraso na tuberização, reduzindo o tamanho dos tubérculos e a quantidade de massa seca, e ainda, favorecer o embonecamento (Soratto et al., 2016, p.420). Por outro lado, a falta de nitrogênio pode acarretar em diminuição da atividade fotossintética, da produção de amido e redução do diâmetro dos tubérculos (Rogeri et al., 2015, p.536).

Desta forma, fica evidente a relação entre a adubação e a qualidade pós-colheita dos tubérculos de batata, fator determinante na aceitação do produto no mercado (Cardoso et al., 2017, p.568). Assim, a adubação pode ser considerada um dos principais fatores que interferem na qualidade da batata, tornando-se necessário estabelecer aplicações equilibradas dos nutrientes para proporcionar aumento na qualidade do seu produto (Fernandes et al., 2015, p.104). Pois no mercado de consumo dos tubérculos o fator com maior influência é a sua aparência como forma, cor, brilho da pele e ausência de defeitos (Feltran et al., 2004, p.600).

Assim, a preferência de consumidores, de produtores e da indústria, são aspectos relevantes, para isso é realizada classificação dos tubérculos, baseada na Instrução Normativa n n 27, de 17 de julho de 2017 do Ministério da Agricultura, Pecuária e Abastecimento (MAPA, 2017) e nas normas de classificação geridas pelo programa brasileiro de modernização da horticultura (CEAGESP, 2015). Deste modo, o presente trabalho objetivou verificar a influência de diferentes adubos orgânicos e doses de nitrogênio na classificação comercial de batata cultivar Asterix.

\section{Metodologia}

O experimento foi realizado na Universidade Federal da Fronteira Sul (UFFS), BR 158, Km 405 (Zona Rural), Laranjeiras do Sul - PR, 85.301-970, latitude 25 26' 40" S, longitude 52 $26^{\circ} 16^{\prime \prime} \mathrm{O}$ e altitude de aproximadamente 806 metros, na horta experimental, nas safras de 2019 e 2020. O solo é classificado como Latossolo Vermelho (EMBRAPA, 2006). O clima segundo a classificação de Köeppen é do tipo $\mathrm{Cfb}$, subtropical mesotérmico úmido com verões temperados, as temperaturas médias ficam abaixo de $18^{\circ} \mathrm{C}$ no mês mais frio e abaixo de $22^{\circ} \mathrm{C}$ no mês mais quente.

Como material propagativo foram utilizadas batatas-sementes da cultivar Asterix. Estas foram armazenadas em câmara fria $\left(4 \pm 1^{\circ} \mathrm{C}\right)$ até a utilização. Para o plantio, foram expostos a ciclos de aquecimento a temperatura ambiente (24 horas) e posterior retorno à câmara fria (3 dias), por no mínimo dois ciclos, com o objetivo de homogeneizar as brotação das batatas-sementes, para planta-las com média de 4 a 5 brotos por batata-semente.

O preparo do solo foi realizado um mês antes da implantação da cultura, com uma subsolagem e duas gradagens seguidas de sulcamento da área para o plantio das batatas-sementes, 15 dias após a emergência das plantas foi realizada a amontoa. Os tratos culturais (manejo fitossanitário) seguiram os padrões recomendados para a região de condução dos experimentos e permitidos para a agricultura orgânica, conforme legislação específica para condução de sistemas de produção orgânica regulamentados pela Lei Federal nº 10.831, de 23 de dezembro de 2003 (Brasil, 2003).

Os tratamentos consistiram de três fontes de nitrogênio oriundas de adubos orgânicos e cinco doses distintas destes adubos. As fontes de nitrogênio orgânico utilizadas no experimento foram: cama de aviário curtida (2,05 de $\mathrm{N} \pm 0,2)$; cama de aviário extrusada $(2,4 \% \mathrm{~N})$ e húmus $(1,1 \%$ de $\mathrm{N} \pm 0,1)$, as doses de nitrogênio testadas foram: 120, 140, 160, 180 e $200 \mathrm{~kg}$ 
N.ha ${ }^{-1}$, além disto, uma fonte de adubo químico sintético, NPK 4-14-8 $(4 \% \mathrm{~N})$, foi utilizada como testemunha nas dose de 160 e $200 \mathrm{~kg} \mathrm{~N} \cdot \mathrm{ha}^{-1}$.

O delineamento experimental foi em blocos ao acaso, com 17 tratamentos (três fontes de nitrogênio $\mathrm{x}$ cinco doses de nitrogênio e duas testemunha) e quatro repetições, totalizando 68 parcelas. Cada parcela mediu 3,6 x 4,8m (17,28 m²), sendo composta por 6 linhas, com 12 plantas por linha, espaçadas em $0,8 \mathrm{~m}$ entre linhas e $0,3 \mathrm{~m}$ entre plantas, sendo o ensaio composto de uma área total de $1.106 \mathrm{~m}^{2}$. As parcelas receberam calagem conforme análise de solo e de acordo com as normas da produção orgânica. Os fertilizantes nitrogenados foram distribuídos em dose total imediatamente antes do plantio dos tubérculos.

Posteriormente a colheita, os tubérculos foram lavados e realizou-se a classificação comercial baseada na Instrução Normativa n 27, de 17 de julho de 2017 do Ministério da Agricultura, Pecuária e Abastecimento (MAPA, 2017) e nas normas do Programa Brasileiro de Modernização da Horticultura (CEAGESP, 2015). Foram coletados aleatoriamente 10 tubérculos por parcela, e avaliadas as variáveis comprimento/diâmetro transversal - calibre $(\mathrm{mm})$, diâmetro $(\mathrm{mm})$, massa fresca $(\mathrm{g})$, defeitos graves (podridão [Pectobacterium spp], coração negro e coração oco), defeitos leves (esfolamento, embonecado, queima, rizoctoniose [Rhizoctonia solani], vitrificação), defeitos variáveis (esverdeamento, perfurações por larva alfinete [Diabrotica speciosa], dano profundo e superficial).

Os resultados foram submetidos a análises estatísticas de variância (anova) a 5\% e os resultados significativos foram posteriormente analisados por regressão.

\section{Resultados e Discussão}

Em todos os tubérculos colhidos não foi observado podridão e coração negro (defeitos graves), queima, rizoctonioze e vitrificação (defeitos leves) e esverdeamento (defeitos variáveis), podendo assim classificar as batatas como comerciais dentro da categoria extra, de acordo com as normas de classificação.

Para as variáveis coração oco, embonecamento, perfurações por larva alfinete e dano profundo e superficial, os resultados não apresentaram significância estatística.

A falta de danos ocasionados por pragas, doenças e condições de cultivo são desejáveis principalmente quando se trata de produtos vegetais que são comercializados in natura (Sediyama et al., 2014, p.831). Nas condições do presente estudo a obtenção de tubérculos com a ausência de danos causados por doenças pode estar relacionados com a qualidade sanitária dos tubérculos sementes utilizados, bem como com as condições adequadas de preparo dos canteiros para a implantação do experimento.

Silva e Menezes, (2007, p.53), Sediyama et al., (2014, p.831) e Cardoso et al., (2015, p.83) citam que a utilização de adubos orgânicos contribui para a sanidade do vegetal por diversificar a produção de substâncias como fenóis e de antibióticos por bactérias, melhorando as condições físicas, químicas e biológicas do solo. E ainda podem contribuir com a inserção de microrganismos benéficos no ambiente do solo que aumentam a disponibilidade de energia para as plantas e competem com possíveis parasitas que possam estar presente no mesmo ambiente, fato que diminui o risco de ocorrência de doenças e pragas durante o cultivo (Santos et al., 2014, p.411).

Malavolta, (2006) e Cardoso et al., (2011, p.596), cotam que adubos orgânicos, como cama de aviário e húmus, utilizados no presente estudo, propiciam a melhoria da qualidade dos solos em que são inseridos, em especial para a cultura da batata. Um ponto relevante é o aumento da porosidade do solo e descompactação o que diminui os danos superficiais nos tubérculos bem como a ocorrência de embonecamento (Malavolta, 2006).

Houve um incremento do comprimento/calibre de tubérculos de batata da cultivar Asterix, conforme o aumento da dose de cama de aviário curtida utilizada. Para as fontes de adubo cama de aviário extrusada e húmus o incremento é crescente 
até a dose de $160 \mathrm{kgN} \cdot \mathrm{ha}^{-1}$. Quando as fontes de adubo são comparadas com a testemunha (adubação NPK) os valores de comprimento são superiores somente para dose de $200 \mathrm{~kg} \mathrm{~N}_{\mathrm{k}} \mathrm{ha}^{-1}$ utilizando a fonte cama curtida (Figura 1).

Figura 1: Comprimento $(\mathrm{mm})$ de tubérculos de batata cv. Asterix em função da aplicação de diferentes fontes e doses de adubo nitrogenado. Universidade Federal da Fronteira Sul - PR, 2021.

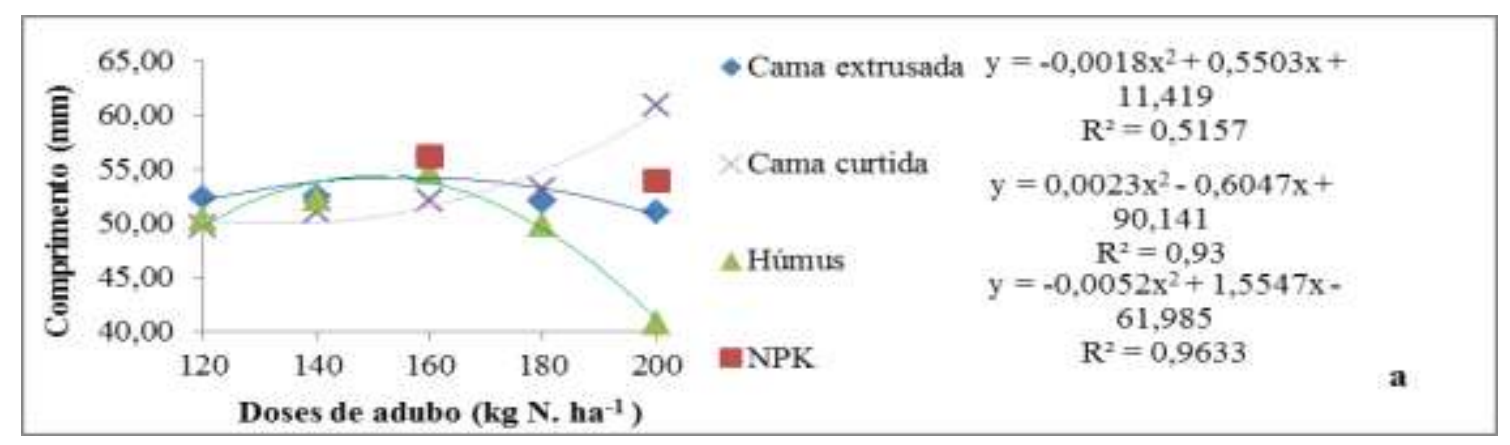

Fonte: Autores.

Paras fontes de adubos nitrogenados cama de aviário extrusada e húmus acredita-se que o teor de nitrogênio disponível para a extração das plantas seja menor, em comparação com o adubo cama de aviário curtida o que pode afetar o crescimento dos tubérculos (Fernandes et al., 2011, p.2041). Isso ocorre, pois durante a preparação da cama de aviário curtida ela passa por um processo de fermentação e um ambiente controlado e vedado, diminuindo a volatilização do nitrogênio, devido ao aquecimento provocado pelo processo de fermentação (Richart et al., 2014, p.4). Desta forma, é possível comparar a progressão do crescimento dos tubérculos onde é fornecida a cama curtida com o adubo sintético NPK, onde o nitrogênio está disponível prontamente para a planta.

Camas de aviário costuma apresentar altos teores de nitrogênio devido à elevada presença de amônia na urina das aves, que fica retida na cama de aviário. De acordo com Passos (2016), altas concentrações de nitrogênio podem comprometer o crescimento de tubérculos de batata, pois acabam intensificando o crescimento vegetativo da planta, acarretando em uma diminuição da distribuição de energia para armazenamento nos tubérculos. Fato evidenciado nos resultados deste ensaio, onde observa-se que quando da disponibilização da dose mais alta do adubo sintético (180 kg N. ha-1) ocorreu decréscimo no padrão de crescimento dos tubérculos, tendo em vista a alta concentração de nitrogênio no adubo NPK fornecido.

O oposto pode ter ocorrido com o adubo fornecido cama de aviário curtida, mesmo na sua maior dose $(200 \mathrm{Kg} \mathrm{N}$. há ${ }^{1}$ ), pois de acordo com Silva e Menezes (2007, p.53), em mistura com o solo a cama de aviário curtida pode volatilizar o nitrogênio anteriormente retido na serragem com maior facilidade, diminuindo assim a sua concentração, fato que beneficia a batateira para a continuação do crescimento dos tubérculos.

Com relação ao comprimento/calibre dos tubérculos quando da utilização da adubação com cama de aviário extrusada as batatas tinham entre 51 e $56 \mathrm{~mm}$ conforme a dose de adubação disponibilizada, se encaixando na classificação de calibre II.1. Quando da utilização de húmus o comprimento/calibre das batatas estava entre 40 a $54 \mathrm{~mm}$ se encaixando também no calibre II.1. Para cama de aviário curtida os valores são de 49 a $60 \mathrm{~mm}$ ficando dentro da classificação de calibre II. Desta forma, de modo geral, as batatas produzidas neste experimento tiveram o tamanho esperado para a cultivar, que comumente apresenta tubérculos médios a grandes com comprimento entre 45 a $85 \mathrm{~mm}$.

Ocorreu aumento do diâmetro dos tubérculos conforme aumento das doses de nitrogênio para todas as fontes de adubo utilizadas no experimento até a dose de $160 \mathrm{~kg} \mathrm{~N} \mathrm{ha}^{-1}$ (Figura 02). Quando as fontes de adubo são comparadas com a testemunha (adubação NPK) os valores do diâmetro são superiores somente para dose de $200 \mathrm{~kg} \mathrm{~N} \cdot \mathrm{ha}^{-1}$ utilizando a fonte cama de aviário curtida $(39,5 \mathrm{~mm})$. Houve um decréscimo nos valores de diâmetro dos tubérculos para as fontes de nitrogênio cama 
de aviário extrusada e húmus a partir da dose $180 \mathrm{~kg} \mathrm{~N}$. ha- ${ }^{-1}$. Para os tubérculos oriundos da adubação com húmus, ocorreu o maior decréscimo nos valores de diâmetro, chegando a $30 \mathrm{~mm}$ quando submetidos a maior dose de nitrogênio $200 \mathrm{~kg}$ N.ha- ${ }^{-1}$ (Figura 2).

Figura 2: Diâmetro (mm) de tubérculos de batata cv. Asterix em função da aplicação de diferentes fontes e doses de adubo nitrogenado. Universidade Federal da Fronteira Sul - PR, 2021.

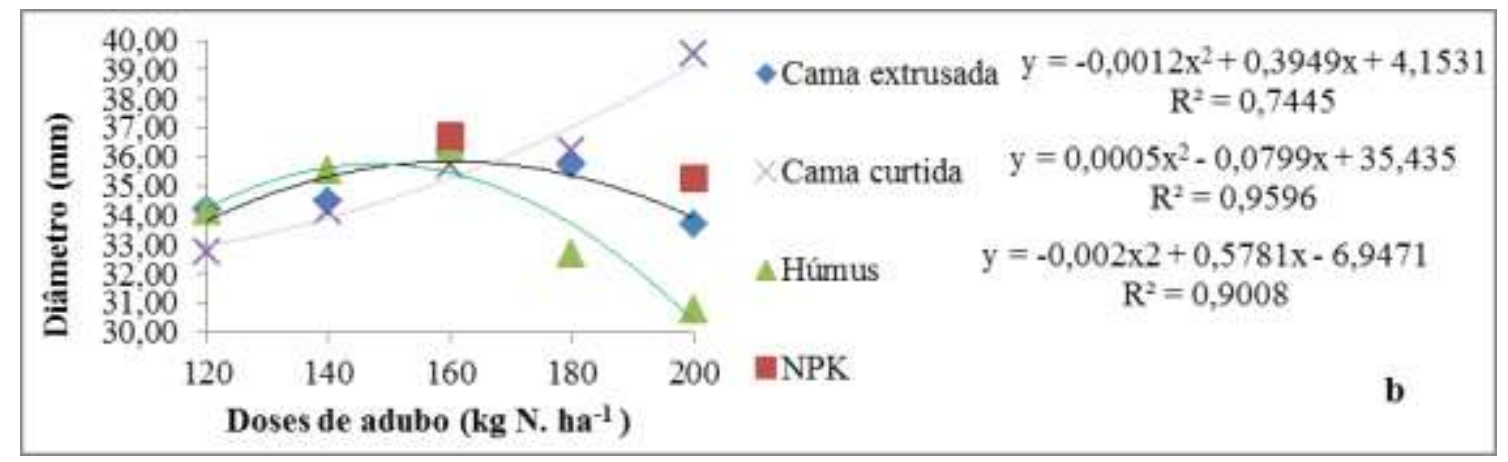

Fonte: Autores.

Devido ao fato de o ciclo produtivo da batateira ser considerado curto, e que há necessidade de uma grande quantidade de nutrientes prontamente disponíveis as plantas, possivelmente nas condições deste experimento, mesmo com o aumento das doses de nitrogênio fornecidos através das fontes cama de aviário extrusada e húmus, não foi possível a extração adequada dos nutrientes pelas plantas, pois, de acordo com Lourenço et al., (2013, p.464) a eficiência da cama de aves como fertilizante depende das condições edafoclimáticas e de características do resíduo, que vão condicionar a capacidade de mineralização dos nutrientes contidos na fração orgânica uma vez que a quantidade disponibilizada às plantas da maioria dos nutrientes é inferior ao teor total contido no resíduo (Rogeri et al., 2015, p.536).

Segundo Borchartti et al., (2011, p.484) o aumento na dose de N pode retardar a maturação dos tubérculos e, com isso, reduzir o diâmetro destes. Além disso, a utilização de doses elevadas de fertilizantes como os nitrogenados, podem causar interações antagonistas com outros nutrientes e limitar a produtividade na cultura da batata (Fernandes \& Soratto, 2012, p.1530). O fato de a testemunha ter apresentados incremento maior de diâmetro, em relação às fontes cama de aviário extrusada e húmus, quando da maior dose, pode ser justificado, pois segundo Palmer et al., (2013, p.85) e Borchartti et al., (2011, p.484) a adubação orgânica, aumenta a capacidade de troca catiônica do solo, elevando o pH e reduzindo o teor de alumínio trocável, aumenta a disponibilidade de nutrientes aplicados por meio de fertilizantes minerais.

Para o diâmetro dos tubérculos na utilização da adubação com cama de aviário extrusada as batatas apresentaram entre 33 e 36 mm, se encaixando na classificação comercial. Quando utilizado a fonte de adubo húmus o diâmetro das batatas estava entre 30 a $36 \mathrm{~mm}$. Segundo a classificação as batatas que apresentavam diâmetro inferior a $33 \mathrm{~mm}$ são consideradas fora do padrão, e isso ocorreu quando utilizadas as maiores doses de adubação de húmus (180 e $200 \mathrm{~kg} \mathrm{~N}$.ha- ${ }^{-1}$ ). Para as outras doses os tubérculos foram considerados dentro da classe comercial. Para cama de aviário curtida os valores obtidos foram entre 32 e $39 \mathrm{~mm}$, onde para a menor dose do adubo $\left(120 \mathrm{~kg} \mathrm{~N}^{\left.-\mathrm{ha}^{-1}\right)}\right.$ as batatas foram classificadas como fora do padrão, para as demais doses a classificação foi comercial. Segundo Fernandes et al., (2011, p.2041) a cultivar Asterix possui tendência de produzir maior porcentagem de tubérculos com diâmetro entre 33 a $45 \mathrm{~mm}$.

Ocorreu aumento da massa fresca dos tubérculos de batata da cultivar Asterix, conforme o aumento da dose de cama de aviário curtida utilizada. Para as fontes de adubo cama de aviário extrusada, húmus e testemunha (adubação NPK) o incremento é crescente até a dose de $160 \mathrm{~kg} \mathrm{~N} \cdot \mathrm{ha}^{-1}$, tendo a testemunha apresentado o acréscimo de massa mais expressivo 
com 48,35 g para essa dose. Entretanto, quando aplicada a maior dose de nitrogênio, $200 \mathrm{~kg} \mathrm{~N} \cdot \mathrm{ha}^{-1}$, os valores de massa fresca são superiores somente para a fonte cama de aviário curtida (42,96 g) (Figura 3).

Figura 3: Massa fresca (g) de tubérculos de batata cv. Asterix em função da aplicação de diferentes fontes e doses de adubo nitrogenado. Universidade Federal da Fronteira Sul - PR, 2021.

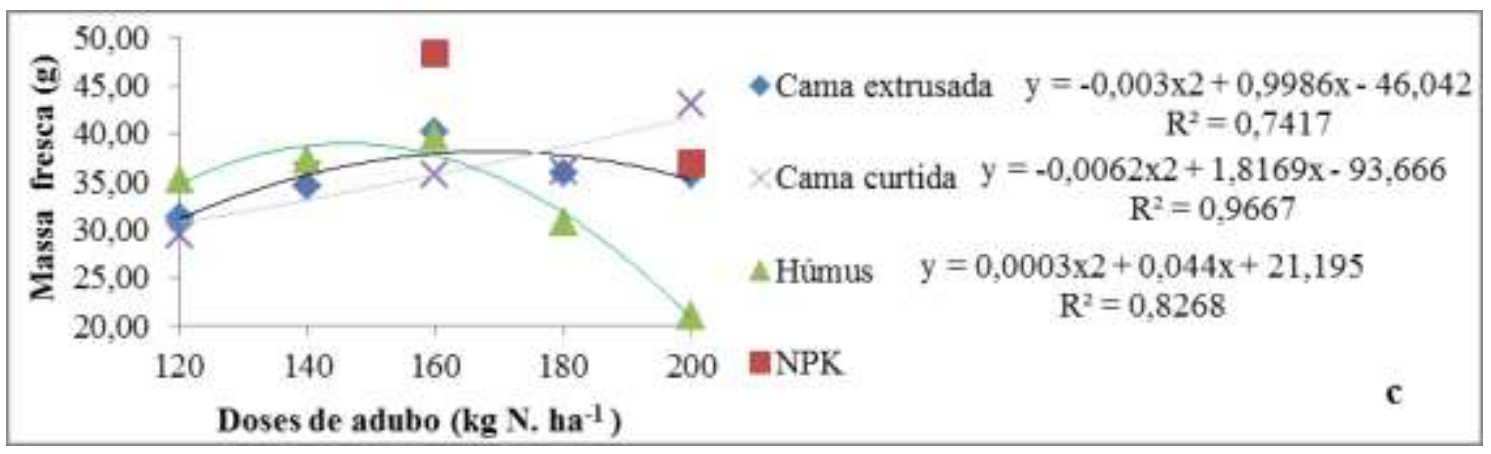

Fonte: Autores.

Com o aumento dos teores de matéria orgânica do solo, o nitrogênio é o principal nutriente liberado na solução do solo, com isso favorece o rendimento da cultura da batata, por ser um dos principais nutrientes exigidos pela cultura, interferindo diretamente no aumento da massa dos tubérculos (Cardoso et al., 2007, p.1731). Neste sentido, Silva et al., (2012, p.559) destacam que a cama de aviário curtida apresenta maior teor de nitrogênio e fósforo disponível, em comparação com os demais adubos, sendo estes nutrientes decisivos para a formação de tubérculos e incremento da massa fresca.

Pereira et al., (2010, p.3653) em trabalho realizado com beterraba (Beta vulgaris L.) observaram um incremento da massa fresca total dos tubérculos produzidos em experimento que comparava as fontes de adubos orgânicos, no qual o incremento das doses de cama de aviário curtida proporcionou aumento da massa dos tubérculo. Eschemback et al., (2014, p.701) em trabalho realizado com batatas da cultivar Asterix, na região do município paranaense de Guarapuava, sob adubação mineral obteve tubérculos com massa fresca média de 37,52 g resultado muito semelhante aos encontrados no presente estudo (36,7 g), sendo estes parâmetros considerados satisfatórios por estarem dentro da classificação comercial.

As informações acima citadas podem ser explicadas; devido ao fato de o nitrogênio $(\mathrm{N})$ ser um dos nutrientes de maior impacto na produtividade das culturas, o $\mathrm{N}$ na forma nítrica (muito presente nas camas de aviário) é rapidamente absorvido, mas também é facilmente lixiviado com a água, perdendo-se. O solo não fixa $\mathrm{N} \mathrm{e,} \mathrm{por} \mathrm{isso,} \mathrm{pode} \mathrm{ocorrer} \mathrm{perda} \mathrm{por}$ lavagem, e também perda sob a forma gasosa (Kawakami, 2015, p.170), sendo que a cultura da batata é especialmente suscetível à perda de N (Cardoso et al., 2007, p.1731). Podendo ter ocorrido essa perda de nitrogênio conforme aumento da dose dos adubos orgânicos cama de aviário extrusada e húmus. O que confere redução do crescimento da parte vegetativa, diminuição da atividade fotossintética e por consequência diminuição da produção do amido que é o principal responsável pelo incremento da massa dos tubérculos (Cardoso et al., 2015, p.82).

Outro fator que dificulta a dosagem correta é a eficiência da adubação nitrogenada. Tal eficiência pode ser definida como a quantidade de $\mathrm{N}$ proveniente do adubo absorvida pela planta, em relação à quantidade de $\mathrm{N}$ aplicado (Kawakami, 2015, p.170). A recuperação do $\mathrm{N}$ pela planta raramente excede $70 \%$ daquela aplicada e, na maior parte das culturas, atinge em média 50\%. Na cultura da batata essa recuperação é até menor, pois a absorção do $\mathrm{N}$ varia entre 13 e $45 \%$, sendo o restante de N lixiviado para as camadas profundas do solo (Song et al., 2014, p.13).

Os tubérculos colhidos para todas as fontes e doses de adubo apresentaram características que os classificam como comerciais de acordo com as normas de classificação comercial baseada na Instrução Normativa nº 27, de 17 de julho de 2017 do Ministério da Agricultura, Pecuária e Abastecimento (MAPA, 2017) e nas normas do Programa Brasileiro de Modernização 
da Horticultura (CEAGESP, 2015). Eschemback et al., (2014, p.701) ressaltam que um fator importante a ser observado é a uniformidade do formato e tamanho dos tubérculos produzidos, muito importante do ponto de vista econômico e de grande relevância para a cadeia produtiva da batata. Fatores estes observados no presente estudo, pois apesar das fontes de nitrogênio apresentar divergência quanto a proporcionarem o crescimento dos tubérculos, estes não tiveram grandes variações em seus diâmetros, comprimento e massa.

\section{Conclusão}

Conclui-se que a fonte de adubo orgânico cama de aviário curtida na dose $200 \mathrm{~kg} \mathrm{~N}$.ha ${ }^{-1}$ favorece a produção de tubérculos de batata cv. Asterix com características aptas para classificação comercial, nas condições impostas pelo experimento.

\section{Agradecimento}

Os autores agradecem pelo apoio oferecido através do Projeto: PES-2019-0625 - Edital No 459/GR/UFFS/2019.

\section{Referências}

ABBA. Associação Brasileira de Batata. A batata como alimento.

Borchartti, L., Silva, I. F., Santana, E. O., Souza, C. \& Ferreira, L. E. (2011) Adubação orgânica da batata com esterco bovino no município de Esperança PB. Revista Ciência Agronômica. 42, $482-487$.

Brasil. Lei n. 10.831, de 23 de dezembro de 2003.

Cardoso, A. D., Alvarenga, M. A. R., Dutra, F. V., Melo, T. L. \& Viana, A. E. S. (2007) Produtividade e qualidade de tubérculos de batata em função de doses e parcelamentos de nitrogênio e potássio. Ciência e Agrotecnologia. 31, 1729-1736.

Cardoso, A. I. I., Ferreira, K. P., Vieira Júnior, R. M. \& Alcarde, C. (2011). Alterações em propriedades do solo adubado com composto orgânico e efeito na qualidade das sementes de alface. Horticultura Brasileira. 29, 594-599.

Cardoso, A. F, Luz, J. M. Q. \& Lana, R. M. Q. (2015) Produtividade e qualidade de tubérculos de batata em função do fertilizante organomineral e safras de plantio. Revista Caatinga. 28, 80-89.

Cardoso, A. D., Alvarenga, M. A. R., Dutra, F. V., Melo, T. L. \& Viana, A. E. S. (2017) Características físico-químicas de batata em função de doses e fracionamentos de nitrogênio e potássio. Revista de Ciências Agrárias. 40, 567-575.

CEAGESP. (2015) Classificação da batata in natura. São Paulo: CEAGESP.

EMBRAPA. (2006) Empresa Brasileira de Pesquisa Agropecuária. Centro Nacional de Pesquisa de Solos. Sistema brasileiro de classificação de solos. (2a ed.), Embrapa Solos, 108 p.

Eschemback, V., Kawakami, J. \& Melo, P. E. (2014) Produtividade e características comerciais de tubérculos de clones e cultivares comerciais de batata. Ambiência Guarapuava.10, $699-706$.

FAO. FAOSTAT. 2020.

Feltran, J. C., Lemos, L. B. \& Vieites, R. L. (2004) Technological quality and utilization of potato tubers. Scientia Agricola. 61, 598-603.

Fernandes, A. M., Soratto, R. P. \& Silva, B. L. (2011) Extração e exportação de nutrientes em cultivares de batata: I Macronutrientes. Revista Brasileira de Ciência do Solo. 35, pp.2039-2056.

Fernandes, A. M. \& Soratto, R. P. (2012) Nutrition, dry matter accumulation and partitioning and phosphorus use efficiency of potato grown at different phosphorus levels in nutrient solution. Revista Brasileira de Ciência do Solo. 36, 1528-1537.

Fernandes, A. M., Soratto, R. P., Moreno, L. A. \& Evangelista, R. M. (2015) Qualidade de tubérculos frescos de cultivares de batata em função da nutrição fosfatada. Bragantia. 74, 102-109.

IBGE. (2014). Sistema IBGE de recuperação automática - SIDRA.

Kawakami, J. (2015) Redução da adubação e doses e parcelamento de nitrogênio no crescimento e produtividade de batata. Horticultura Brasileira. 33, pp.168-173.

Lourenço, K. S., Corrêa, J. C., Ernani, P. R., Lopes, L. D. S. \& Nicoloso, R. D. S. (2013) Nutrient uptake and yield of common bean fertilized with poultry litters and mineral nutrients. Revista Brasileira de Ciência do Solo. 37, 462-471. 
Malavolta, E. (2006). Manual de nutrição mineral de plantas. Ceres. 638 p.

MAPA (2017). Ministério da Agricultura, Pecuária e Abastecimento/secretaria de defesa agropecuária. Instrução normativa No 27, Edição: 141, Seção: 1, Página: 12.

Matos, E. S., Mendonça, E. S., Leite, L. F. C. \& Galvão, J. C. C. (2008) Estabilidade de agregados e distribuição de carbono e nutrientes em Argissolo sob adubação orgânica e mineral. Pesquisa agropecuária brasileira. 43, 1221-1230.

Maraus, P. F., Santos, H. S., Brandão Filho, J. U. T., Buzanini, A. C. \& Barbieri, B. R. (2011) Eficiência de inseticidas no controle de Diabrotica speciosa na cultura da batata. Horticultura Brasileira. 29, 774-749.

Musyoka, M. W., Adamtey, N., \& Cadisch, G. (2017) Effect of organic and conventional farming systems on nitrogen use efficiency of potato, maize and vegetables in the Central highlands of Kenya. European Journal of Agronomy. 86, 24-36.

Palmer, M. W., Cooper, J. Tétard-Jones, C., Średnicka-Tober, D., Barański, B., Eyre, M., Shotton, P.N., Volakakis, N., Cakmak, I., Ozturk, L., Leifert, C., Wilcockson, S.J. \& Bilsborrow, P.E. (2013) The influence of organic and conventional fertilisation and crop protection practices, preceding crop, harvest year and weather conditions on yield and quality of potato (Solanum tuberosum) in a long-term management trial. European Journal of Agronomy. 49, 83-92

Passos, S. Desempenho de cultivares de batata em sistema orgânico: crescimento, produtividade e resposta a requeima e a larva alfinete. 2016. Universidade Estadual do Centro-Oeste, UNICENTRO, Guarapuava, PR.

Pereira, A. L. S., Morais Júnior, O. P., Mendes, R. T. \& Neri, S. C. (2010) Adubação orgânica e mineral na cultura da beterraba. Horticultura Brasileira. 28, 3651-3658

Queiroz, L. R. M., KawakamI, J., Muller, M. M., Oliari, I. C. R., Umburanas, R. C \& Eschemback, V. (2013) Adubação NPK e tamanho de batata-semente no crescimento, produtividade e rentabilidade de plantas de batata. Horticultura Brasileira. 31, 119-127.

Reichert, L. J., Gomes, M. C., Schwengber, J. E. \& Pereira, A. S. (2013) Evaluation of organic potato production systems in the southern Rio Grande do Sul State, Brazil. Horticultura Brasileira. 31, pp. 220-230.

Richter, A. S. \& Randomski, M. I. (2009) Manejo da fertilidade do solo da cultura da batata. In: Nazareno, N. R. X. DE (Ed.). Produção orgânica de batata: potencialidades e desafios. IAPAR, p. 37-70.

Richarter, A., Gibbert, R. M. \& Müller, E. J. (2014) Perdas de nitrogênio por volatilização de amônia da cama de frango em função do manejo de aplicação em argissolo vermelho. Synergismus Scyentifica. 9, 1-10.

Rogeri, D. A., Ernani, P.R., Lourenço, K.S., Cassol, P.C. \& Gatiboni, L.C. (2015) Mineralization and nitrification of nitrogen from poultry litter applied to soil. Revista Brasileira de Engenharia Agrícola e Ambiental. 19, 534-540

Santos, A. P. G., Viana, T. V. A., Sousa, G. G., Azevedo, B. M., Santos, A. M. (2014) Produtividade e qualidade de frutos do meloeiro em função de tipos e doses de biofertilizantes. Horticultura Brasileira. 4, 409-416.

Sediyama, M. A. N., Santo, I. C. \& Lima, P. C. (2014) Cultivo de hortaliças no sistema orgânico. Revista Ceres. 61, 829-837

Silva, T. O. \& Menezes, R. O. C. (2007) Adubação orgânica da batata com esterco e, ou, Crotalaria Juncea. II - disponibilidade de n, p e k no solo ao longo do ciclo de cultivo. Revista Brasileira de Ciência do Solo, n.31, p.51-61.

Silva, G. O. D., Castro, C. M., Terres, L. R., Rohr, A., Suinaga, F. A. \& Pereira, A. S (2012) Componentes de produção, ciclo vegetativo e peso específico de clones de batata. Horticultura Brasileira. 30, pp. 557-560.

Silva, O. G., Pereira, A. S., Bail, F. E., PonijalekI, R. \& Carvalho, A. D. F. (2017) Response of potato cultivars to increasing levels of NPK. Revista Ceres. 64, 492-499.

Song, C., Guan, Y., Wang, D., Zewudie, D. \& Li, F. M. (2014) Palygorskite-coated fertilizers with a timely release of nutrients increase potato productivity in a rain-fed cropland. Field Crops Research. 166, 10-17.

Soratto, R. P., Fernandes, A. M. \& Job, A. L. G. (2016) Nutrição e adubação de hortaliças: Nutrição e adubação da cultura da batata. 1, $419-446$. 